\title{
PENDIDIKAN KARAKTER PADA SISWA SEKOLAH DASAR DI JEPANG DAN INDONESIA
}

\author{
Fitri Alfarisy, Fransiska Aulia Fitriyani, Fatiya Mutsaqqofa, Nisa Tiara \\ Kusumasari \\ Universitas Diponegoro, Semarang, Indonesia \\ Email: fitrialfarisy@staff.undip.ac.id, fransiskaauliaf@students.undip.ac.id, fatiyaqofa \\ @ students.undip.ac.id, nisatiarakusumasari@students.undip.ac.id
}

\begin{abstract}
Abstrak
Penelitian ini dilatarbelakangi oleh maraknya fenomena penyimpangan sosial yang berhubungan dengan moral dan budi pekerti. Demikian, muncul pertanyaan, apakah pendidikan karakter yang diajarkan secara teoritis mampu dipahami dengan benar dan diterapkan dalam kehidupan sehari-hari. Karakter dapat didefinisikan sebagai sebuah perilaku konsisten dari seseorang dalam kehidupannya. Perilaku ini menyangkut nilai nilai moral,akhlak dan budi pekerti. Sedangkan pendidikan karakter merupakan proses penanaman nilai-nilai kebaikan kepada individu agar siap berbaur dengan masyarakat dan mengambil keputusan yang bijak. Untuk menuju sebuah bangsa yang gemilang diperlukan karakter yang baik dan konsisten dari setiap warga negara. Penerapan pendidikan karakter pada anak-anak Sekolah Dasar merupakan salah satu upaya pencegahan terjadinya nir moral berkelanjutan pada generasi penerus bangsa. Karena pendidikan seharunya tidak hanya mendidik siswa menjadi generasi yang pandai dan berpengetahuan, tetapi juga harus berkarakter,bermoral dan berbudi pekerti yang baik. Anak-anak Sekolah Dasar menjadi objek dalam upaya awal penanaman karakter yang baik karena pada rentang usia 7-11 tahun, mereka tengah berada dalam perkembangan kognitif operasi konkrit. Pada tahapan ini, anak-anak mengandalkan rasionalitas logika mereka untuk menentukan sebuah keputusan. Maka dari itu, tahap ini diperlukan pemahaman yang tepat. Selain upaya yang dilakukan pemerintah melalui sistem pendidikan dalam kurikulum yang mewajibkan adanya pendidikan karakter, peran keluarga dan masyarakat juga diperlukan untuk memaksimalkan hasil pendidikan karakter di sekolah. Penelitian ini menggunakan metode kualitatif dengan pendekatan studi literatur yang berpedoman pada kurikulum pendidikan Sekolah Dasar di Jepang dan Indonesia. Meskipun kedua negara tersebut memiliki permasalahan krisis karakter yang berbeda, namun keduanya sama-sama menerapkan pendidikan karakter pada kurikulum negaranya. Tentu ini menunjukan betapa pentingnya karakter yang baik bagi generasi penerus yang diharapkan mampu menjadi tonggak menuju bangsa yang gemilang.
\end{abstract}

Kata Kunci : pendidikan karakter; anak-anak; sekolah dasar; indonesia; jepang

$\begin{array}{ll}\text { How to cite: } & \text { Alfarisy. F. et.al (2021 Pendidikan Karakter pada Siswa Sekolah Dasar di Jepang dan Indonesia, 6(2), } \\ & \text { Syntax Literate: Jurnal Ilmiah Indonesia } \\ \text { E-ISSN: } & \text { 2548-1398 } \\ \text { Published by: } & \text { Ridwan Institute }\end{array}$

Published by: $\quad$ Ridwan Institute 
Fitri Alfarisy, Fransiska Aulia Fitriyani, Fatiya Mutsaqqofa, Nisa Tiara Kusumasari

\begin{abstract}
This research is motivated by the widespread phenomenon of social deviation related to morals and character. Thus, the question arises whether the theoretically taught character education can be properly understood and applied in everyday life. The character can be defined as a consistent behavior of a person in his life. This behavior involves moral values, character, and character. While character education is a process of instilling good values into individuals so that they are ready to mingle with society and make wise decisions. To get to a glorious nation requires good and consistent character from every citizen. The application of character education to elementary school children is one of the efforts to prevent the occurrence of unsustainable morals in the nation's next generation. Because education should not only educate students to become smart and knowledgeable generations, but also must have good character, morality, and character. Elementary school children become objects in the initial effort to cultivate good character because, at the age range of 7-11 years, they are in the cognitive development of concrete operations. At this stage, children rely on their logical rationality to make a decision. Therefore, this stage requires proper understanding. In addition to the efforts made by the government through the education system in the curriculum that requires character education, the role of family and community is also needed to maximize the results of character education in schools. This study uses a qualitative method with a literature study approach that is guided by the elementary school education curriculum in Japan and Indonesia. Although the two countries have different character crises, they both apply character education to their country's curriculum. Of course, this shows how important good character is for the next generation which is expected to be a milestone towards a glorious nation
\end{abstract}

Keywords: character education; children; elementary school; indonesia; japan

\title{
Pendahuluan
}

Melihat banyaknya fenomena pada kehidupan sehari-hari yang berhubungan dengan kedisiplinan dan ketaatan pada aturan serta norma yang ada, menjadikan kita bertanya apakah teori mengenai karakter yang baik, benar dapat dipahami oleh masyarakat. Berbagai hal kecil seperti pelanggaran lalu lintas, datang terlambat ke sekolah, tidak mengerjakan pekerjaan rumah, dan sebagainya. Perilaku ini menunjukan bahwa ada permasalahan mengenai pendidikan karakter yang diterapkan. Dengan masyarakat yang berkarakter, tentunya harapan untuk menjadi bangsa yang unggul akan mudah tercapai. Lalu, bagaimanakah pendidikan karakter diterapkan pada tingkat pendidikan sekolah dasar?

Setiap negara tentu memiliki sistem pendidikan karakter yang berbeda-beda. Menurut (Mulyasa, 2011:32) Pendidikan karakter diartikan sebagai pendidikan nilai, budi, moral, dan watak yang bertujuan untuk mengembangkan kemampuan siswa dalam memutuskan baik dan buruk dalam kehidupan sehari-hari. Oleh sebab itu, pendidikan karakter secara psikologis mencakup dimensi moral reasoning, moral feeling, dan moral behavior. 
Jepang menjadi salah satu negara yang menerapkan sistem pendidikan karakter pada usia dini, karena menganggap bahwa karakter merupakan modal utama untuk membangun masyarakat yang berkualitas. Keseriusan pemerintah Jepang untuk menjadikan masyarakatnya memiliki karakter yang baik, tidak didapatkan dengan mudah. Keseriusan tersebut dimulai sejak dini, yakni pada fase Sekolah Dasar (SD). Sekolah Dasar biasanya terdiri atas anak-anak antara usia 5-11 tahun, atau Taman Kanak-kanak (TK) sampai kelas enam (Harmon, Harmon, \& Jones, 2005).

Selain Jepang, Indonesia juga menerapkan kebijakan pendidikan karakter pada sistem pendidikannya. Pendidikan karakter tersebut merupakan dasar utama untuk membangun sebuah bangsa yang unggul. Pendidikan karakter di Indonesia berisi mengenai nilai, moral, karakter, budaya, ataupun nilai-nilai Pancasila (Hasan, 2012:84). Undang-undang nomor 20 tahun 2003 tentang Sistem Pendidikan Nasional berbunyi, maka pendidikan budaya dan karakter bangsa diartikan sebagai proses internalisasi serta penghayatan nilai-nilai budaya dan karakter bangsa yang dilakukan peserta didik secara aktif dibawah bimbingan guru, kepala sekolah dan tenaga kependidikan serta diwujudkan dalam kehidupannya di kelas, sekolah, dan masyarakat. Dengan banyaknya masyarakat yang sadar akan pentingnya pendidikan karakter, maka akan mampu mewujudkan bangsa menjadi bangsa yang unggul. Pendidikan karakter pada jenjang sekolah dasar, tertuang dalam kurikulum 2013. Pendidikan karakter di Indonesia tidak hanya diterapkan pada satu mata pelajaran khusus tetapi diterapkan di setiap mata pelajaran yang ada. Pemerintah mulai memperhatikan mengenai pentingnya pendidikan karakter untuk membentuk Sumber Daya Manusia (SDM) yang berkualitas.

Maka dari itu murid sekolah dasar dijadikan sebagai objek penelitian dalam menganalisis pendidikan karakter di Jepang dan di Indonesia, karena pendidikan karakter pada siswa sekolah dasar merupakan tingkat pertama pembentukan karakter Sumber Daya Manusia yang berkualitas. Sehingga kedepannya sumber daya tersebut dapat membantu meningkatkan kualitas suatu negara menuju generasi yang unggul. Oleh karena itu, penelitian ini memunculkan beberapa rumusan masalah yaitu:

1. Mengapa pendidikan karakter pada tingkat sekolah dasar begitu penting?

2. Bagaimana hasil yang dicapai dari pendidikan karakter di Indonesia pada tingkat sekolah dasar?

3. Bagaimana hasil yang dicapai dari pendidikan karakter di Jepang pada tingkat sekolah dasar?

\section{Metode Penelitian}

Penelitian ini menggunakan metode kualitatif dengan pendekatan studi literatur. Metode penelitian studi literatur merupakan metode penelitian dengan teknik pengumpulan informasi dan data seperti buku referensi, artikel, catatan, serta jurnal yang relevan dengan permasalahan yang dibahas (Sari \& Asmendri, 2020). Metode studi literatur digunakan untuk memperoleh sumber data yang relevan dengan permasalahan yang dibahas. Sumber data yang diperoleh termasuk dalam data primer 
dan sekunder. Pedoman pendidikan karakter di kurikulum Indonesia dan Jepang sebagai data primer dan jurnal-jurnal yang terkait sebagai data sekunder.

\section{Pembahasan}

\section{Pendidikan karakter pada Sekolah Dasar sangatlah penting}

Pendidikan karakter merupakan langkah awal pembentukan karakter pada diri individu. Pendidikan seharusnya tidak hanya melahirkan individu yang berprestasi dalam bidang sains dan teknologi, namun pendidikan seharusnya juga mampu melahirkan insan berkarakter unggul dan berpengetahuan (Putri, n.d.). Pendidikan diharapkan dapat melahirkan generasi baru dengan kecerdasan dalam pengetahuan dan kebijaksanaan dalam berperilaku. Individu yang berkarakter baik di kemudian hari akan menjadi sumber daya manusia yang dapat menyokong sebuah negara menjadi bangsa yang unggul dalam moral dan budi pekerti. Sebuah karakter dapat terbentuk melalui rutinitas atau kebiasaan yang berulang sehingga melekat menjadi sebuah karakter. Seperti yang dikemukakan oleh Sudrajat (2011) pendidikan memiliki dua tujuan, yakni menjadikan manusia menjadi cerdas dan mengarahkan manusia menjadi pribadi yang baik dalam moral dan budi pekerti. Mengarahkan manusia menjadi pribadi yang baik bukanlah perkara yang mudah. Oleh sebab itu problematika yang berkaitan dengan moral dan budi pekerti menjadi persoalan sendiri yang harus ditemukan solusinya. Salah satunya adalah dengan pencegahan melalui sistem pendidikan. Pendidikan karakter pada Sekolah Dasar bertujuan untuk membentuk dan menyiapkan lebih awal anak-anak sebagai generasi penerus bangsa yang bermoral dan memiliki budi pekerti. Karakter pada sebuah bangsa menjadi poin penting mengingat setiap warga negara wajib menjaga dan menjunjung tinggi martabat bangsa dan negaranya.

Anak-anak pada tingkat Sekolah Dasar menjadi permulaan yang tepat untuk menerapkan penanaman pendidikan karakter. Berdasarkan teori yang dikemukakan oleh Piaget (1952) anak pada rentang usia 7-11 tahun memiliki permulaan pola pikir rasional yang artinya anak-anak mengedepankan hal-hal yang dapat dicerna secara logis oleh akal mereka untuk menyelesaikan sebuah masalah. Seandainya terjadi perbedaan antara pikiran dan persepsi, antara teori dan praktek, maka dalam situasi seperti ini anak-anak akan menggunakan logika mereka untuk menentukan sebuah keputusan. Teori ini disebut dengan teori perkembangan kognitif anak tahapan operasioal konkrit. Hal ini didukung oleh Lickona (2004) yang mengemukakan tujuh alasan mendasar mengapa pendidikan karakter di Sekolah Dasar menjadi sangat penting untuk diterapkan, yakni :

1. Pendidikan karakter di sekolah, menjamin anak-anak mendapat permulaan yang baik untuk membentuk kepribadiannya

2. Upaya tambahan meningkatkan prestasi akademik

3. Sebagian anak-anak tidak bisa membentuk karakter yang terlalu kuat atas dirinya di tempat lain

4. Menyiapkan anak-anak agar siap dalam kehidupan masyarakat majemuk

5. Sebagai solusi awal problematika moral-sosial dan pencegahan agar generasi selanjutnya menjadi generasi yang lebih baik. 
6. Menyiapkan anak-anak agar siap bersaing menyongsong tujuan negara menjadi bangsa yang unggul

7. Mempertahankan nilai-nilai budaya yang menjadi kepribadian bangsa

Dengan pendapat diatas tentu menjadi semakin jelas mengapa pendidikan karakter ini penting untuk diterapkan. Penanaman karakter di sekolah, dapat mencapai keberhasilan apabila didukung oleh keluarga dan lingkungan. Sejatinya, pembentukan karakter pertama pada anak-anak adalah melalui kebijaksanaan dan kasih sayang dalam pola didikan orang tua serta bagaimana penerapan kebiasaan dalam keluarga. Sedangkan lingkungan berperan sebagai suplemen tambahan yang menjadi contoh utama anak-anak mengamalkan karakter dalam bermasyarakat. Dalam kehidupan bermasyarakat inilah nantinya kematangan sebuah karakter akan diuji. Menilik fenomena yang terjadi pada masyarakat majemuk, kebijaksanaan seorang individu dalam bertingkah laku turut menjadi cermin keberhasilan karakter yang ditanamkan dalam dirinya.

\section{Pendidikan Karakter di Indonesia}

Pendidikan karakter sejak dini merupakan hal yang penting dalam bidang pendidikan moral, apalagi dalam era digital seperti sekarang ini. Yang membuat banyak anak atau pelajar lebih suka untuk menyendiri dan lebih berkutat dengan ponsel pintarnya, menjadikan kurangnya rasa untuk bersosialisasi dengan orang lain. Banyak negara di luar sana yang telah mengajarkan pendidikan karakter dan memiliki output yang baik. Begitu juga dengan Indonesia yang telah menerapkan pendidikan karakter di tingkat sekolah dasar melalui kurikulum 2013, yang mengharapkan supaya memiliki karakter yang baik nantinya. Kebijakan pemerintah ini tentu saja sangat didukung oleh banyak pihak, karena memiliki tujuan yang sangat bagus. Sebagai pelajar dituntut untuk menjadi pintar, aktif dan juga tidak lupa untuk memiliki karakter yang baik. Jika seseorang tidak memiliki karakter yang baik, dapat memunculkan dampak negatif yang tidak kita inginkan. Supaya pendidikan karakter bisa diterapkan dengan benar, selain diatur dalam kurikulum 2013, pemerintah melakukan gerakan PPK (Penguatan Pendidikan Karakter).

Dalam kurikulum 2013 sendiri, bertujuan untuk mengubah atau memperbaiki sikap-sikap para pembelajar agar memiliki nilai-nilai moral yang bagus. Mengajarkan bahwa sikap, pengetahuan dan keterampilan salah satu cara untuk pembelajar khususnya siswa Sekolah Dasar supaya dari kecil sudah terlatih untuk berperilaku yang sesuai dengan nilai-nilai yang ada (Haryati, 2017).

Keberhasilan pendidikan karakter juga bergantung kepada keluarga, pengajar di sekolah serta lingkungan anak tersebut. Keluarga adalah orang yang paling dekat, lalu di sekolah ada para guru yang akan mengajarkan pendidikan karakter di luar yang diajarkan oleh keluarga. Di dalam sekolah yang berperan untuk menjadi orang tua adalah para guru. Maka dari itu, para pengajar juga perlu di training terlebih dahulu dalam pendidikan karakter. Supaya dapat mengajarkan serta memberikan contoh kepada siswa-siswi Sekolah Dasar. Jika bertujuan ingin generasi penerus bangsa memiliki 
karakter yang bagus, harus memiliki pengajar yang berkualitas juga. Pada pelajaran di sekolah khususnya siswa sekolah dasar, pendidikan karakter juga diajarkan dalam pelajaran pendidikan kewarganegaraan (PKn). Dalam pelajaran PKn, diajarkan supaya pelajar bisa menjadi seseorang yang memiliki rasa nasionalisme, sopan santun dan ketika di kelas dapat aktif. Hanya saja penerapannya dirasa masih kurang. Tetapi sejak kurikulum 2013 dibuat serta diberlakukan, pemerintah menerapkan pembelajaran secara tematik dalam beberapa pelajaran di Sekolah Dasar. Dalam pembelajaran secara tematik ini, mengajarkan kepada pelajar untuk terlibat aktif di dalam kelas. Karena aktif sendiri merupakan salahsatu tujuan dari kurikulum 2013 untuk membuat para pelajar berani untuk mencoba dan ini adalah salahsatu pembentukan karakter. Dengan seperti ini tujuan negeri ini untuk memiliki pemuda-pemudi yang berpendidikan karakter akan terwujud.

Lalu ada yang namanya gerakan PPK (Penguatan Pendidikan Karakter), ini diharapkan untuk menguatkan sistem pendidikan karakter di Indonesia. Ada lima nilai karakter utama yang diprioritaskan. Seperti religius, nasionalis, mandiri, gotong royong dan integritas. Indonesia merupakan negara beragama, jadi nilai religius adalah nilai pertama yang harus benar-benar diterapkan. Karena menunjukkan atau mencerminkan beriman kepada Tuhan Yang Maha Esa dan cinta damai serta bisa bertoleransi. Nilai nasionalis itu cara bersikap maupun cara berpikir untuk mementingkan kepentingan bangsa di atas kepentingan pribadi. Lalu ada mandiri yaitu sikap supaya tidak bergantung kepada orang lain. Tidak lupa kita harus melakukan gotong royong. Gotong royong merupakan tindakan yang menghargai kerjasama dan berkomunikasi secara berkelompok. Ketika sedang dihadapkan sebuah masalah, kita harus memiliki rasa untuk gotong royong supaya masalah bisa terselesaikan. Dan yang terakhir ada integritas, ini adalah nilai bagaimana Anda bisa dipercaya oleh orang lain. Dalam perkataan, tindakan maupun pekerjaan.

\section{Pendidikan Karakter di Jepang}

Jepang terkenal sebagai negara yang menomorsatukan pendidikan. Pendidikan di Jepang tidak hanya mengarah kepada akademik dan non akademik saja, tetapi juga pendidikan moral. Sejak April 2018, Jepang menerapkan pendidikan karakter di bangku sekolah dasar sebagai suatu mata pelajar yang disebut 道徳教育 (doutoku-kyouiku). Dalam mata pelajaran tersebut terdapat 4 perspektif yang wajib untuk diajarkan yaitu.

1. Keahlian dalam mengenali diri sendiri

- Dapat membedakan perbuatan baik dan perbuatan buruk

- Tidak berbohong atau menipu

- Dapat menjaga kesehatan dan keselamatan diri sendiri

- Tidak egois

- Belajar dengan giat

2. Keahlian dalam bersosialisasi dengan orang lain

- Dapat berperilaku baik dengan orang lain 
- Berterimakasih kepada orang yang telah berbuat baik

- Dapat berkata dengan perkataan baik kepada orang lain

- Dapat membantu teman yang kesusahan

3. Keahlian dalam menghormati kehidupan, alam dan ciptaan Nya

- Dapat memahami indahnya kehidupan dan menghargai kehidupan

- Dapat mengenal dan memperlakukan alam sekitar dengan baik

- Dapat memperlakukan hewan dan tumbuhan dengan baik

4. Keahlian bersosialisasi dalam kelompok dan masyarakat

- Dapat menepati janji dan aturan

- Dapat menghargai pekerjaan orang lain

- Dapat menghormati orang yang lebih tua

- Dapat menghormati guru dan pengurus yang ada di sekolah

- Memiliki ketertarikan terhadap budaya dan kebiasaan daerah

- Membiasakan diri terhadap orang lain yang berbeda kebudayaan

Tujuan dari mata pelajaran khusus moral ini untuk menumbuhkan moralitas yang baik sebagai dasar dari kehidupan yang lebih baik. Siswa diharapkan mampu berperilaku sesuai dengan moral yang diajarkan. Dengan begitu, moralitas siswa akan meningkat, sehingga meminimalisir adanya perilaku menyimpang yang dilakukan oleh siswa (Pearce, 2021).

Mata pelajaran khusus moral berpedoman pada buku ajar diterbitkan oleh Kementerian Pendidikan, Budaya, Olahraga, Sais, dan Teknologi Jepang. Buku tersebut berjudul わたしたちの道徳 (watashitachi no doutoku) yang artinya moralitas kita. Buku tersebut dibagi menjadi 2 bab yaitu bab membaca dan bab menulis. Bab membaca berisi mengenai cerita dan pepatah orang-orang yang hebat. Sementara itu, bab menulis berisi mengenai instruksi dan sebuah pertanyaan yang berkaitan dengan perasaan dan keinginan pribadi siswa. Dengan menulis siswa dapat mengenal diri sendiri dan menjadi kesempatan pengajar untuk mengetahui cara berfikir, perasaan, dan dapat membimbing mereka secara individu. Selain buku pedoman, Kementerian Pendidikan, Budaya, Olahraga, Sains, dan Teknologi Jepang juga menerbitkan buku pelengkap yang berjudul 心のノート (kokoro no nooto) yang nantinya akan digunakan oleh para siswa untuk menulis bagaimana perasaan mereka masing-masing.

Dalam pelajaran khusus moral metode pengajaran yang lebih sering digunakan yaitu diskusi dan bermain peran atau drama. Menurut hasil survei Universitas Gakukei Tokyo, persentase penggunaan metode mengajar diskusi sebanyak 76,7\% dan metode bermain peran sebanyak $71 \%$. Dengan berdiskusi kelompok, siswa mendiskusikan ide secara efektif dengan berbagi, meringkas, dan membandingkan ide-ide yang ada dalam kelompok diskusi (ISHIDA, 2018).

\section{Kesimpulan}


Berdasarkan penelitian yang dilakukan dapat disimpulkan bahwa, pendidikan karakter merupakan upaya untuk menanamkan karakter baik agar dapat diamalkan dalam kehidupan sehari-hari sebagai suatu kebiasaan. Nilai moral, budi pekerti dan akhlak merupakan poin utama dalam penanaman karakter. Pendidikan seharusnya tidak hanya melahirkan insan yang cerdas, namun turut pula melahirkan insan berkarakter yang baik. Ditambah pula saat ini banyak fenomena sosial yang menunjukan krisis karakter pada masyarakat yang menyadarkan kita bahwa, pendidikan karakter merupakan hal yang penting dan wajib diupayakan keberhasilannya. Anak-anak sebagai generasi bangsa menjadi tahap awal dalam keseriusan penanaman karakter yang baik. Pada rentang usia 7-11 tahun, anak-anak berada dalam tahapan perkembangan kognitif operasi konkrit. Pada tahapan ini anak-anak mempertimbangkan suatu keputusan melalui rasionalitas logika mereka. Keberhasilan pendidikan karakter ini,menjadi tanggung jawab bersama tidak hanya pemerintah saja. Namun keluarga dan masyarakat juga turut berperan sebagai suplemen tambahan dalam upaya penanaman karakter pasa anak-anak.

Pendidikan karakter telah ditetapkan diberbagai negara dan memiliki output yang baik. Indonesia dan Jepang adalah salah satu negara yang menerapkan pendidikan karakter. Di Indonesia sendiri, pendidikan karakter telah diatur dalam kurikulum 2013 dan pemerintah juga melakukan PPK (Penguatan Pendidikan Karakter). Pada kurikulum 2013, diharapkan para pelajar termasuk siswa Sekolah Dasar (SD) untuk pintar, aktif serta memiliki karakter yang bagus. Lalu untuk menguatkan pendidikan karakter yang diajarkan di sekolah, pemerintah sendiri melakukan gerakan PPK. Diharapkan melalui gerakan ini, karakter yang akan dibangun sejak dini akan bertahan dan dapat mengembangkan kualitas atau potensi anak.

Di Jepang, pendidikan karakter dijadikan sebagai mata pelajaran khusus yaitu 道徳教育 (doutoku-kyouiku) yang mengajarkan siswanya untuk lebih mengenal diri sendiri, masyarakat dan alam. Bahkan, pemerintah membuat sebuah buku pedoman yang berjudul わたしたちの道徳 (watashitachi no doutoku) yang di dalamnya terdapat dua inti pembelajaran yaitu menulis dan membaca. Dengan menulis, siswa diharapkan mampu mengenal dan memahami diri mereka sendiri sehingga pengajar dapat mengetahui cara berpikir siswa. Sementara itu, di topik membaca siswa disuguhkan dengan cerita dan pepatah orang-orang hebat. Selain itu, pemerintah juga menerbitkan buku pendamping yang berjudul 心のノート (kokoro no nooto) yang nantinya akan digunakan siswa untuk menulis perasaan pribadi. 


\section{BIBLIOGRAPHY}

Harmon, D. A., Harmon, D., \& Jones, T. S. (2005). Elementary education: A reference handbook. ABC-CLIO.Google Scholar

Haryati, S. (2017). Pendidikan Karakter dalam Kurikulum 2013. Tersedia Secara Online Di: Http://Lib. Untidar. Ac. Id/Wp-Content/Uploads [Diakses Di Bandung, Indonesia: 17 Maret 2017]. Google Scholar

ISHIDA, M. (2018). How Coaching Influences Teachers' Beliefs and Students' SelfRegulated Learning in High School English Classes. Mie University. Google Scholar

Lickona, T. (2004). Character matters: How to help our children develop good judgment, integrity, and other essential virtues. Simon and Schuster. Google Scholar

Pearce, D. R. (2021). Homogenous representations, diverse realities: Assistant language teachers at elementary schools. The Language Teacher. Google Scholar

Piaget, J. (1952). Jean Piaget. Google Scholar

Putri, D. P. (n.d.). Pendidikan karakter pada anak sekolah dasar di era digital. Google Scholar

Sari, M., \& Asmendri, A. (2020). Penelitian Kepustakaan (Library Research) dalam Penelitian Pendidikan IPA. Natural Science: Jurnal Penelitian Bidang IPA Dan Pendidikan IPA, 6(1), 41-53. Google Scholar

Sudrajat, A. (2011). Mengapa pendidikan karakter? Jurnal Pendidikan Karakter, 1(1). Google Scholar

\section{Copyright holder:}

Fitri Alfarisy, Fransiska Aulia Fitriyani, Fatiya Mutsaqqofa, Nisa Tiara Kusumasari (2021)

First publication right:

Syntax Literate: Jurnal Ilmiah Indonesia

This article is licensed under:

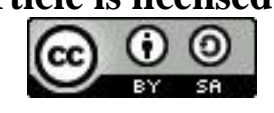

